\title{
RANCANG BANGUN MONITORING SUHU DAN KELEMABABAN KANDANG GUNA MEMPERMUDAH KINERJA PETERNAK BERBASIS ARDUINO
}

\author{
Rizki Fahmin Kafafi \\ Program Studi Teknik Informatika S1, Fakultas Teknologi Industri \\ Institut Teknologi Nasional Malang, Jalan Raya Karanglo km 2 Malang, Indonesia \\ rizkifahmin@gmail.com
}

\begin{abstract}
ABSTRAK
Usaha peternakan ayam, baik ayam petelur maupun ayam pedaging merupakan suatu usaha yang prospeknya masih bagus. Hal ini karena kebutuhan maupun permintaan daging ayam dan telur ayam cenderung meningkat dari tahun ke tahun. Seiring dengan meningkatnya pertumbuhan penduduk dan meningkatnya permintaan akan kebutuhan daging ayam, hal tersebut dapat menandakan bahwa peluang usaha di bidang peternakan ayam pedaging ini masih terbuka lebar, oleh karena itu banyak pengusaha yang berminat untuk membuka usaha di bidang peternakan ayam pedaging.

System ini dibuat berdasarkan masalah yang serimg dialami oleh perternak, yang harus melihat dan mengecek suhu pada kandang secara manual, dan harus pergi langsung ke kandang. Dengan adanya system monitong ini diharapkan mampu untuk mempermudah peternak dalam memonitoring kandang dengan hanya melihat website yang telah di sediakan, melalui desktop maupun handphone.

Perancangan sistem monitoring suhu secara otomatis juga dapat mengontrol suhu dan kelembaban pada kandang menggunakan mikrokontroler Arduino UNO sebagai pengendali utama, DHT11 sebagai sensor suhu Sn kelembaban pada kandang dan Exhaustfan sebagai driverkipas yang mengatur suhu, dan lampu bolam sebangai pemanasnya. Mikrokontroler akan memerintahkan Exhaustfan untuk bekerja, apabila suhu yang terukur diatas dari batasan suhu yang ditetapkan dan akan memerintahkan relay untuk menyalakan atau mematikan lampu bolam apabila suhu yang terukur dibawah dari batasan suhu yang telah ditentukan.
\end{abstract}

Kata kunci : monitoring suhu kandang, DHT 11, module esp8266, ESP8266, internet of things

\section{PENDAHULUAN}

Ayam broiler merupakan salah satu peluang bisnis yang menjanjikan dan telah menjadi pilihan dalam bisnis ternak unggas. Kelebihan dari bisnis ayam broiler adalah masa panen yang cukup singkat, yaitu lebih kurang 40 hari. Selain itu pemasaran daging ayam broiler cukup mudah karena masyarakat sangat gemar mengkonsumsi daging ayam.

Dalam penelitian Tarmuzi (2004), dikatakan bahwa keunggulan karakteristik ayam broiler menandakan bahwa ayam broiler merupakan strain unggul yang berasal dari daerah subtropis dan produktivitasnya tidak dapat disamakan bila dipelihara di daerah tropis. Faktor lingkungan, genetik dan manajemen pemeliharaan menjadi penghambat dalam pencapaian produksi, kemudian untuk mencapai pertumbuhan yang optimal usaha yang diperlukan diantaranya dengan pemberian makanan yang bergizi tinggi, perbaikan manajemen dengan pemberian temperatur lingkungan pemeliharaan yang optimal.

Tujuan dari penelitian ini adalah mengidentifikasi masalah-masalah yang ada pada kandang ayam broiler dan selanjutnya melakukan evaluasi desain agar dapat mempermudah kinerja para peternak ayam broiler.

Dengan adanya alat alat ini, akan mempermudahkan peternak untuk mengecek suhu kandang sewaktu waktu bila di perlukan. Peternak juga dimudahkan jika ingin mengubah suhu kapan saja jika keadaan diluar kemampuan pengamatan system.

Berdasarkan latar belakang masalah yang telah ditentukan dapat di rumuskan permasalahan yang akan dibahas adalah bagaimana merancang hardware yang dapat digunakan untuk memantau suhu dan kelembababan pada kandang menggunakan sensor DHT11 dan dapat di lihat dari web, serta mendapatkan nofitikasi berupa email.

\section{TINJAUAN PUSTAKA}

\subsection{Monitoring Suhu}

Indonesia merupakan Negara agraris yang sangat subur, mayoritas penduduk nya hidup dari sector pertanian, perkebunan, peternakan, dan nelayan. Salah satu peternaan yang banyak terdapat di Indonesia adalah peternakan ayam broiler atau ayam potong. Bagi peternak ayam broiler sangat perlu menjaga kondisi kandang 
dan pemeliharaan ayam dengan baik untuk menghasilkan ayam dengan kualiatas yang baik pula.

Banyak peternak yang masih menggunakan cara manual untuk dalam memberi pakan dan menjaga suhu kandang ayam. Cara ini masih dirasa kurang efisien dan efektif. Maka dalam penelitian ini dirancang sebuah alat pemberi pakan dan control suhu secara otomatis berbasis PLC(programmable logic controller). [1]

Hannif izzatul islam juga menjelaskan dalam jurnal nya bahwa kebutuhan akan system yang dapat melakukan monitoring dan pengontrolan jarak jauh semakin meningkat tiap tahun nya, sejalan dengan kehidupan manusia, sehingga dapat mempermudah hidup manusia. Sehingga terciptalah sebuah system control dan monitoring jarak jauh yang memanfaatkan mikrokontroler dikarenakan biayanya murah dan luas pemanfaatya.

Untuk menciptakan system tersebut diperlukan sebuah aplikasi dan kontroler yang dapat berkolaborasi, dimana aplikasi tersebut dapat mengakses perangkat system melalui jaringan computer. Aplikasi ini berfungsi sebagai interface, pengolah data, dan control jarak jauh. [2]

\subsection{Arduino Uno}

Arduino Uno adalah board mikrokontroler yang di dalamnya terdapat mikrokontroler, penggunaan jenis mikrokontroler-nya berbeda beda tergantung spesifikasinya. Pada Arduino Uno diguanakan mikrokontroler berbasis ATmega 328. Memiliki 14 pin input dari output digital dimana 6 pin input tersebut dapat digunakan sebagai output PWM dan 6 pin input analog, $16 \mathrm{MHz}$ osilator kristal, koneksi USB, jack power, ICSP header, dan tombol reset.

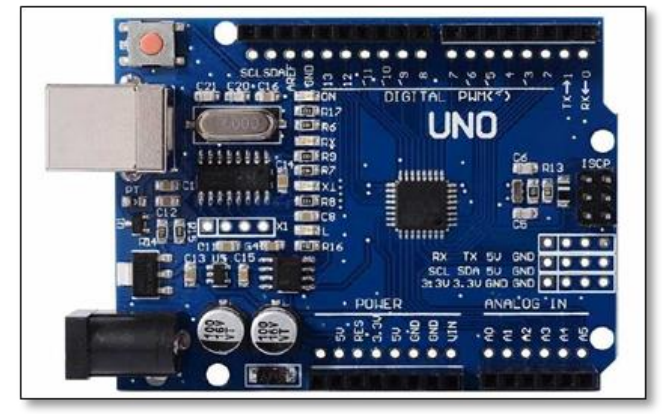

Gambar 2.1 Arduino UNO

\subsection{Modul Wifi ESP8266}

ESP8266 adalah chip terintegrasi yang di rancang untuk kebutuhan terhubungnya dunia. Ia menawarkan solusi jaringan wifi yang lengkap dan mandiri, yang memungkinkan untuk menjadi host atau mentranfer semua fungsi jaringan wifi dan prosesor aplikasi lain. ESP8266 memiliki kemampuan pengolahan dan penyimpanan onboard yang kuat, yang memungkinkan untuk diintegrasikan dengan sensor dan aplikasi perangkat khusus lain melalui GPIOs dengan pengembangan yang mudah loading waktu yang minimal.

ESP8266 yang berkolaborasi dengan Arduino uno digunakan untuk mengirim data suhu dan kelembaban dari hasil pembacaan sensor DHT11, Data akan dikirim ke server. ESP8266 menggunakan ATcommand sebagai perintah-perintah dasarnya.

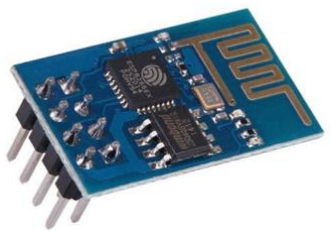

Gambar 2.2 Modul Wifi ESP8266

\subsection{Sensor DHT 11}

DHT11 adalah sensor Suhu dan Kelembaban, dia memiliki keluaran sinyal digital yang dikalibrasi dengan sensor suhu dan kelembaban yang kompleks. Teknologi ini memastikan keandalan tinggi dan sangat baik stabilitasnya dalam jangka panjang. mikrokontroler terhubung pada kinerja tinggi sebesar 8 bit. Sensor ini termasuk elemen resistif dan perangkat pengukur suhu NTC. Memiliki kualitas yang sangat baik, respon cepat, kemampuan anti-gangguan dan keuntungan biaya tinggi kinerja.Setiap sensor DHT11 memiliki fitur kalibrasi sangat akurat dari kelembaban ruang kalibrasi.

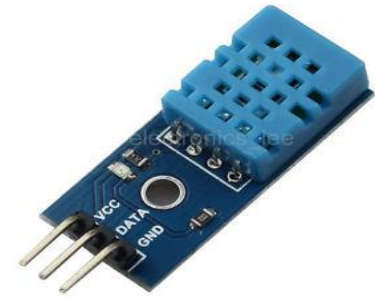

Gambar 2.3 Modul DHT 11

\subsection{Lampu Bolam}

Lampu bolam atau lampu dop adalahsumber cahaya buatan yang dihasilkan melalui penyaluran arus listrik melalui filament yang kemudian memanas dan menghasilkan cahaya. Kaca yang menyelubingi filament pemanas tersebut menghalangi udara masuk untuk berhubungan dengan filament sehingga tidak akan merusak langsung akibat oksidasi. Pada kandang ayam biasanya lamu jenis ini 
deigunbakan untuk menghangatkan ayam yang masih kecil.

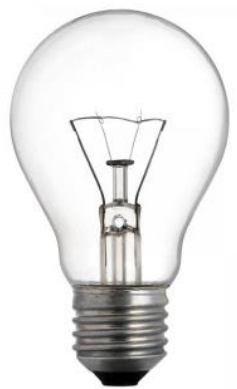

Gambar 2.5 Lampu dop

\subsection{Exhaust Fan}

Alat ini berfungsi untuk menghisap udara panas di dalam kandang dan membuangnya ke luar dan pada saat bersamaan menghisap udara segar di luar masuk ke dalam kandang. Fungsi lain exhaust fan adalah mengatur volume udara yang akan disirkulasikan pada kandang agar suhu tetap tejaga

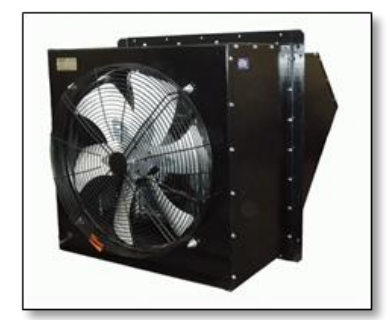

Gambar 2.6 ExhaustFan

\section{METODE PENELITIAN}

\subsection{Flowchart Hardware}

Pada flowchart software dijelaskan bahwa, alur pengukuran suhu suhu dimulai dengan sensor DHT11 mengecek suhu pada ruangan kandang dan system melihat apakah suhu tersebut sudah termasuk optimal atau belum. jika suhu lebih dari optimal, maka kipas pendingin akan menyala, dan jika kurang maka pemanas yang aka menyala. 


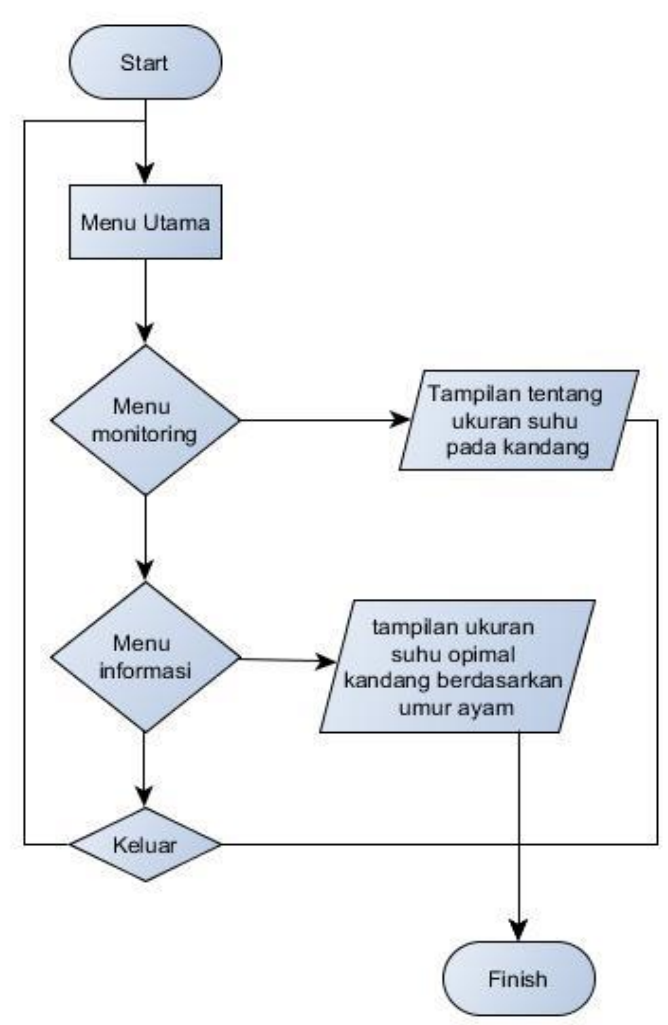

Gambar 3.2 Flowchart Software

\subsection{Skema Rangkaian Alat}

Skema rangkaian alat merupakan gambaran dari model alat yang akan dibuat. Skema rangkaian keseluruhan hardware monitoring suhu kandang ayam, skema hardware dapat dilihat pada gambar 3.3.

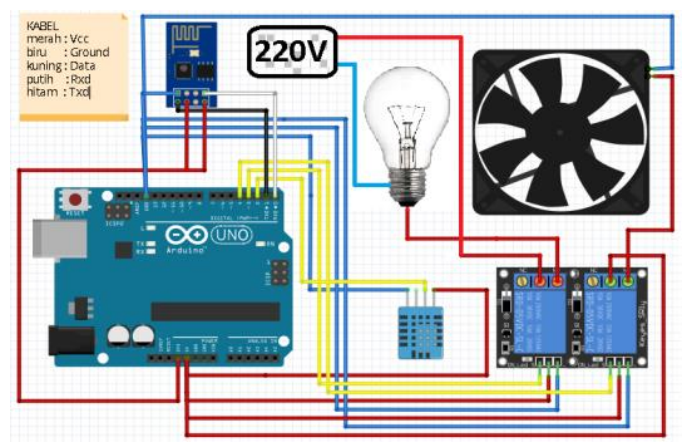

Gambar 3.3 SkemaRangkaian Alat

Alokasi konfigurasi dan penggunaan pin pada rangkaian alat ditunjukan pada Tabel 3.1 sebagai berikut:
Tabel 3.1 Tabel Konfigurasi Pin Rangkaian Alat

\begin{tabular}{|c|c|}
\hline \multirow{2}{*}{ Arduino } & Perangkat Lain \\
\cline { 2 - 2 } & Modul wifi ESP8266 \\
\hline Ground & Ground \\
\hline$+3.3 \mathrm{~V}$ & VCC \\
\hline D4 & RX \\
\hline D3 & TX \\
\hline & Sensor DHT 11 \\
\hline $5 \mathrm{~V}$ & VCC \\
\hline A2 & DATA \\
\hline Ground & Ground \\
\hline & Relay \\
\hline Ground & Ground \\
\hline $5 \mathrm{~V}$ & VCC \\
\hline A3 & Input \\
\hline & Relay \\
\hline $5 \mathrm{~V}$ & VCC \\
\hline Ground & Ground \\
\hline & Lampu Bolam \\
pin & Data \\
\hline & Exhaustfan \\
\hline $5 \mathrm{~V}$ & VCC \\
\hline Ground & Ground \\
\hline
\end{tabular}

\subsection{Struktur Menu}

Website monitoring suhu kandang ayam di bangun menggunakan Bahasa pemrograman PHP serta menggunakan database MySQL. Struktur menu website yang akan penulis susun seperti gambar dibawah ini.

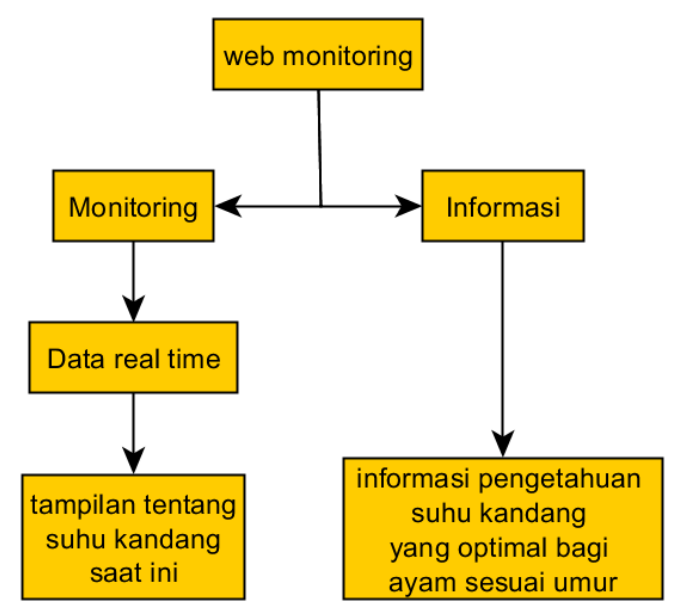

Gambar 3.4 Struktur Menu website 
Keterangan :

Menu Home : Digunakan untuk menampilkan halaman utama.

Menu Monitoring : Digunakan untuk menampilkan informasi yaitu data realtime menampilkan keadaan suhu tiap waktu dan menampilkan informasi.

Menu Informasi : Digunakan untuk menampikan informasi berupa ketentuann keadaan suhu yang layak bagi ayam berdasarkan umur nya.

Menu about : Digunakan untuk memberikan informasi bagaimana cara menggunakan website.

\section{HASIL DAN PEMBAHASAN}

\subsection{Hasil Implementasi Hardware}

Hasil rangkaian hardware alat monitoring kandang ayam dan hasil sampai saat ini seperti pada Gambar 4.1.

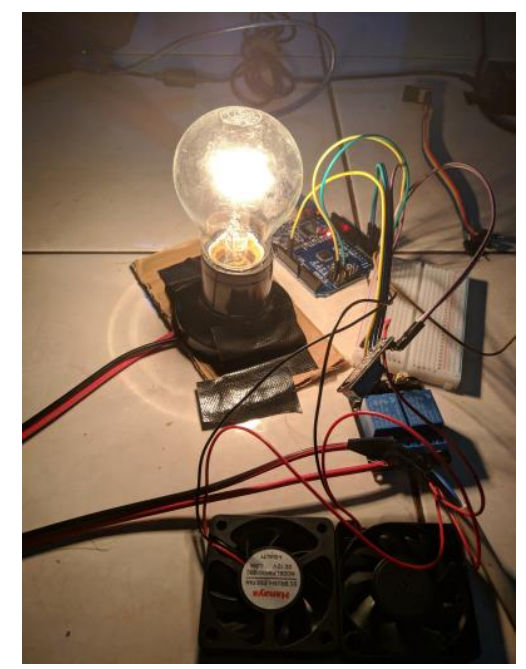

Gambar 4.1 Hasil Rangkaian Hardware

\subsection{Hasil Implementasi Software}

Halaman Beranda Halaman beranda seperti pada Gambar 4.2 digunakan untuk menampilkan hasil pemantauan suhu, kelembaban, dan udara secara real time.

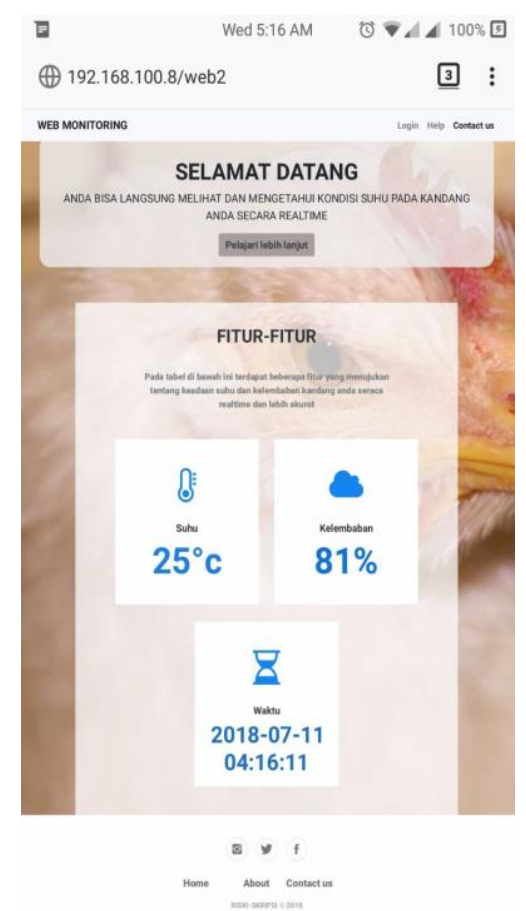

Gambar 4.2 Halaman web versi mobile

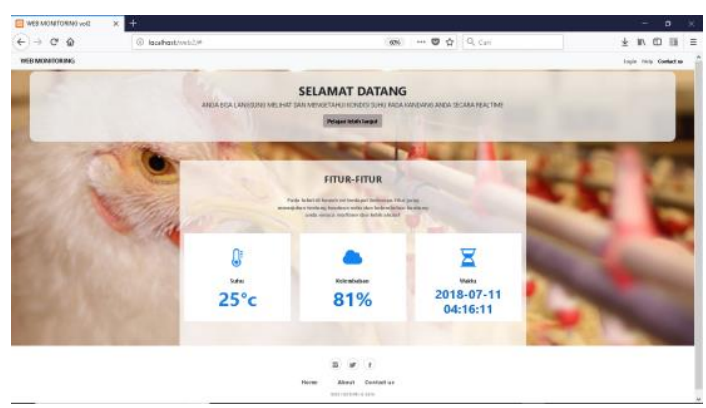

Gambar 4.3 Halaman web versi dekstop

\subsection{Pengujian Hardware}

Pengujian dilakukan dengan melihat respon kecepatan dari lampu bolam dan kipas saat terjadi perubahan suhu secara berkala.

\subsubsection{Pengujian Suhu Sensor DHT 11}

Sensor DHT 11 diuji dengan memberikan pemanasan secara tidak langsung, kemudian nilai keluaran akan dibandingkan dengan thermometer ruangang Setelah didapatkan hasil dari kedua alat pengukuran tersebut, akan diketahui presentasi kesalahan dari DHT11. Dari pengujian didapatkan data sebagai berikut 
Tabel 4.1 Hasil Pengujian Sensor Suhu DHT 11

\begin{tabular}{|c|c|c|c|}
\hline $\begin{array}{c}\text { Waktu } \\
(\mathbf{s})\end{array}$ & $\begin{array}{c}{ }^{\mathbf{}} \mathbf{C} \\
\text { DHT11 }\end{array}$ & $\begin{array}{c}{ }^{\mathbf{o}} \mathbf{C} \\
\text { Termoter } \\
\text { ruangan }\end{array}$ & $\begin{array}{c}\text { Presentasi } \\
\text { Kesalahan }\end{array}$ \\
\hline 1 & 21 & 21 & $0 \%$ \\
\hline 5 & 21 & 22 & $2,4 \%$ \\
\hline 10 & 24 & 24 & $0 \%$ \\
\hline 15 & 21 & 22 & $3,1 \%$ \\
\hline 20 & 22 & 23 & $4,0 \%$ \\
\hline 25 & 23 & 24 & $0,0 \%$ \\
\hline 30 & 21 & 22 & $0,6 \%$ \\
\hline 35 & 23 & 24 & $3,7 \%$ \\
\hline 40 & 21 & 21 & $0 \%$ \\
\hline 45 & 21 & 22 & $1,4 \%$ \\
\hline 50 & 24 & 24 & $0,5 \%$ \\
\hline \multicolumn{3}{|c|}{ Rata-Rata Kesalahan } & $1.5 \%$ \\
\hline
\end{tabular}

\subsubsection{Pengujian Modul Wifi}

Dari prosedur diatas dilakukan pengujian dengan melakukan pengiriman data dari Arduino uno ke database melalui koneksi Wireless Module ESP8266. Untuk melakukan pengujian ini akan diambil sampel pengiriman data sebanyak 30 kali untuk mengetahui respon yang terima saat melakukan pengiriman data, dapat dilihat pada tabel 4.4 .

\begin{tabular}{|c|c|c|}
\hline Data ke- & Respon & Delay \\
\hline 1 & $\mathrm{Ya}$ & 10detik \\
\hline 2 & Tidak & - \\
\hline 3 & $\mathrm{Ya}$ & 11detik \\
\hline 4 & Ya & 9detik \\
\hline 5 & $\mathrm{Ya}$ & 10detik \\
\hline 6 & Tidak & - \\
\hline 7 & $\mathrm{Ya}$ & 11detik \\
\hline 8 & $\mathrm{Ya}$ & 11detik \\
\hline 9 & $\mathrm{Ya}$ & 11detik \\
\hline 10 & Tidal & - \\
\hline 11 & $\mathrm{Ya}$ & 10detik \\
\hline 12 & $Y_{a}$ & 10detik \\
\hline 13 & Tidak & - \\
\hline 14 & $\mathrm{Ya}$ & 10detik \\
\hline 15 & $\mathrm{Ya}$ & 10detik \\
\hline 16 & $\mathrm{Ya}$ & 11detik \\
\hline 17 & Tidak & - \\
\hline 18 & $\mathrm{Ya}$ & 10detik \\
\hline 19 & $\mathrm{Ya}$ & 11detik \\
\hline 20 & $\mathrm{Ya}$ & 10detik \\
\hline 21 & $\mathrm{Ya}$ & 11detik \\
\hline 22 & $\mathrm{Ya}$ & 11detik \\
\hline 23 & Tidak & - \\
\hline 24 & $\mathrm{Ya}$ & 11detik \\
\hline 25 & $\mathrm{Ya}$ & 11detik \\
\hline 26 & $\mathrm{Ya}_{\mathrm{a}}$ & 11detik \\
\hline 27 & $\mathrm{Ya}$ & 11detik \\
\hline 28 & $\mathrm{Ya}$ & 11detik \\
\hline 29 & $\mathrm{Ya}$ & 11detik \\
\hline 30 & $\mathrm{Ya}$ & 11detik \\
\hline
\end{tabular}

\subsection{Pengujian Software}

Pengujian software pada penelitian ini dengan dilakukannya pengujian kompabilitas website terhadap web browser bertujuan untuk mengetahui apakah halaman website yang dibuat dapat menampilkan keseluruhan data sesuai dengan perancangan tidak hanya satu web browser yang sering digunakan pada umumnya. Hasil uji coba kompabilitas website terhadap web browser seperti ditunjukan pada Tabel 4.2.

Pada tahap pengujian kompabilitas website terhadap web browser $98 \%$ berjalan pada ketiga web browser. Namun pada web browser mobile, tab header akan berantakan jika dibuka tanpa menggukan fitur desktop site. 4.2 Pengujian Kompabilitas Software terhadap Web Browser

\begin{tabular}{|c|l|c|c|c|}
\hline No & \multicolumn{1}{|c|}{$\begin{array}{c}\text { Aspek } \\
\text { Pengujian }\end{array}$} & $\begin{array}{c}\text { Mozilla } \\
\text { Firefox } \\
\text { versi } \\
\mathbf{3 3 . 0 . 1}\end{array}$ & $\begin{array}{c}\text { Web } \\
\text { browser } \\
\text { mobile }\end{array}$ & $\begin{array}{c}\text { Google } \\
\text { Chrome } \\
\text { versi } \\
\mathbf{5 4 . 0}\end{array}$ \\
\hline 2. & $\begin{array}{l}\text { Menampilkan } \\
\text { informasi Suhu, } \\
\text { kelembaban } \\
\text { secara realtime }\end{array}$ & $\checkmark$ & $\checkmark$ & $\checkmark$ \\
\hline $\begin{array}{l}\text { Menampilkan } \\
\text { pop-up tentang } \\
\text { informasi suhu } \\
\text { dan kelembaban }\end{array}$ & $\checkmark$ & $\checkmark$ & $\checkmark$ \\
\hline 3. & $\begin{array}{l}\text { Menampilkan } \\
\text { responsifibitas } \\
\text { web secara } \\
\text { keseluruhan }\end{array}$ & $\checkmark$ & $X$ & $\checkmark$ \\
\hline
\end{tabular}

\subsection{Pengujian User}

Tabel 4..5 Berikut table jumlah nilai pengujian terhadap 10 user

\begin{tabular}{|c|l|c|c|c|}
\hline \multirow{2}{*}{ No } & \multicolumn{1}{|c|}{ Pertanyaan } & \multicolumn{3}{|c|}{ Nilai } \\
\cline { 2 - 4 } 1 & $\begin{array}{l}\text { Apakah pengunaan } \\
\text { menu atau fitur aplikasi } \\
\text { mudah digunakan? }\end{array}$ & 8 & 2 & - \\
\hline 2 & $\begin{array}{l}\text { Apakah aplikasi sudah } \\
\text { sesua kebutuhan ? }\end{array}$ & 6 & 2 & 2 \\
\hline 3 & $\begin{array}{l}\text { Apakah aplikasi mudah } \\
\text { dioperasikan? }\end{array}$ & 8 & 2 & - \\
\hline 4 & $\begin{array}{l}\text { Apakah aplikasi } \\
\text { bermanfaat bagi } \\
\text { pengguna? }\end{array}$ & 6 & 4 & - \\
\hline 5 & $\begin{array}{l}\text { Apakah aplikasi } \\
\text { mempunyai } \\
\text { kemampuan yang sudah } \\
\text { diharapkan? }\end{array}$ & - & 5 & 5 \\
\hline Ket : & $\begin{array}{l}\text { B. Baik } \\
\text { C. Cukup } \\
\text { K. Kurang }\end{array}$ & & \\
\hline
\end{tabular}




\section{KESIMPULAN DAN SARAN}

5.1. Kesimpulan

Dengan adanya penelitian ini, maka didapatkan beberapa kesimpulan yaitu:

1. Sistem yang dibuat merupakan system pemantauan suhu, kelembaban, dan kualitas udara dapat diakses melalui website.

2. Penggunaan website monitoring incubator bayi ini bersifat automatic system dimana semua proses I/O dilakukan oleh komponen alat pemantau (embedded system) dan pengolahan dilakukan oleh website sendiri sehingga pengguna dapat menggunakan website secara praktis.

3. Pada pengujian sensor MQ-135 diperoleh hasil prosentase kesalahan tertinggi yaitu $12 \%$ dan prosentase kesalahan terendah yaitu $0 \%$ dan ratarata kesalahan sebesar $3.5 \%$.

4. Pada pengujian sensor DHT 11 diperoleh hasil prosentase kesalahan tertinggi yaitu $4.0 \%$ dan prosentase kesalahan terendah yaitu $0.5 \%$ dan rata-rata kesalahan sebesar $1.5 \%$.

5. Pada tahap pengujian kompabilitas website menggunakan 3 browser yaitu Mozilla Firefox 33.0.1, Internet Explorer Windows 8.1 dan Google Chrome 54.0 dengan prosentase kompabilitas $98 \%$ berjalan sesuai perancangan.

\subsection{Saran}

Website pemantauan kualitas udara ini masih memiliki kekurangan sehingga dapat dikembangkan agar menjadi lebih baik lagi. Untuk pengembangan lebih lanjut adapun beberapa saran:
1. Pemantauan udara dapat ditambah beberapa inkubator lain jadi tidak hanya menampilkan informasi udara 1 inkubator namun banyak incubator dengan 1 monitoring

2. Perlu ditambahkan DC air fan untuk penghangat yang lebih praktis sehingga kehangat merata di dalam inkubator

\section{DAFTAR PUSTAKA}

[1] Hazami, Syafi'i. 2015. Model pengatur suhu dan kelembaban kandang ayam broiler menggunakan mikrokontroler ATMega328 dan sensor DHT11, Volume 3, no 2 .

[2] Islam, Hannif izzatul. 2016. Sistem kendali suhu dan pemantauan kelembaban udara ruangan berbasis arduino uno dengan menggunakan sensor DHT22 dan passive infrared (PIR), Volume 5.

[3] Binanto, Iwan. 2005. Membangun Web Server (Apache $+P H P+M y S Q L$ ) menggunakan FreeBSD. Yogyakarta

[4] Nurahmadi, fauzan. 2011. Sistem control dan monitoring suhu jarak jauh memanfaatkan Embedded system mikroprosessor W5100 dan ATMega8535, Vol1, no2.

[5] Uray, Desvianda "Model Sistem Deteksi Suhu Dan Waktu Inkubator PPembuat Yogurt Menggunakan Modul DHT 11 Dan Smartphone Android Berbasis Mikrokontroller ATMEGA328”, Bogor. 